\title{
Student behavior in undergraduate physics laboratories: Designing experiments
}

\author{
Bei Cai® ${ }^{1, *}$ Lindsay A. Mainhood $\odot,{ }^{2, \dagger}$ Ryan Groome $\odot,{ }^{1}$ \\ Corinne Laverty $\odot,{ }^{3}$ and Alastair McLean $\odot^{1, \sharp}$ \\ ${ }^{1}$ Department of Physics, Engineering Physics, and Astronomy, Queen's University, \\ Kingston, Ontario K7L 3N6, Canada \\ ${ }^{2}$ Faculty of Education, Queen's University, Kingston, Ontario K7M 5R7, Canada \\ ${ }^{3}$ Centre for Teaching and Learning, Queen's University, Kingston, Ontario K7L 3N6, Canada
}

(Received 6 June 2020; accepted 1 July 2021; published 20 August 2021)

\begin{abstract}
We investigated physics students' behavior in a second-year laboratory by analyzing transcribed audio recordings of laboratory sessions. One student group was given both a problem and procedure and asked to analyze and explain their results. Another was provided with only the problem and asked to design and execute the experiment, interpret the data, and draw conclusions. These two approaches involved different levels of student inquiry and they have been described as guided and open inquiry, respectively. The latter gave students more opportunities to practice "designing experiments," one of the six major learning outcomes in the recommendations for the undergraduate physics laboratory curriculum by the American Association of Physics Teachers. Qualitative analysis was performed of the audio transcripts to identify emergent themes and it was augmented by quantitative analysis for a richer understanding of student behavior. An important finding is that significant improvements can be made to undergraduate laboratories impacting student behavior by increasing the level of inquiry in laboratory experiments. This is most easily achieved by requiring students to design their own experimental procedures.
\end{abstract}

DOI: 10.1103/PhysRevPhysEducRes.17.020109

\section{INTRODUCTION}

As physics is an experimental science, it is natural that physicists receive some of their education in a laboratory environment where personal observation and physical experimentation can take place. American Association of Physics Teachers (AAPT) identifies the foremost goals of physics laboratories as learning to think like a physicist, referred to as "habits of mind," and constructing a view of the physical world through experimental design, data collection, analysis, and interpretation [1]. The AAPT recommendations for the undergraduate physics laboratory curriculum outlines six learning outcomes that underpin achievement of these goals; these are constructing knowledge, modeling, designing experiments, developing technical and practical laboratory skills, analyzing and visualizing data, and communicating physics.

\footnotetext{
*beicai@queensu.ca

Present address: Office of Research Services, Queen's University, Kingston, Ontario K7L 3N6, Canada.

lindsay.mainhood@queensu.ca

tmcleana@queensu.ca

Published by the American Physical Society under the terms of the Creative Commons Attribution 4.0 International license. Further distribution of this work must maintain attribution to the author(s) and the published article's title, journal citation, and DOI.
}

The traditional mode of instruction in physics laboratories frequently uses the "recipe" approach where students are given a detailed procedure. This has recently been described as a form of passive teaching, masquerading as active engagement [2]. When students follow detailed instructions without having to grapple with their own conceptual understanding, they are not challenged to think for themselves. Fraser et al. argue that, despite the fact they are using physics apparatus, they are solely "hands-on" and not "heads-on" [2].

There is emerging interest in student-driven inquiry laboratories that allow students to take ownership of their experimental work $[3,4]$. The inquiry approach provides opportunities to build conceptual understanding and scientific skills through active participation in design and decision-making processes as defined by the principles of constructivist learning [5]. Inquiry-based learning is endorsed as learner-focused pedagogy that reinforces achievement of learning outcomes including subject content and thinking skills. It has been shown to improve knowledge of subject content [6] and science process skills [7]. More specifically, it aids conceptual understanding, analysis of experimental errors, interpretation and representation of data, and evaluation of results as well as enjoyment of learning $[8,9]$.

A review of 138 inquiry studies in elementary-secondary education concluded that inquiry is a means to prompt 
active thinking, increase conceptual understanding, and draw conclusions from data [10]. A meta-analysis of 22 studies over a ten-year span on the same population confirmed that inquiry prompts active engagement in higher-order thinking skills, such as proposing and evaluating results, which helps students understand science [11]. In a comparison of different levels of inquiry, SpronkenSmith and Walker [12] found that inquiry questions serve as a trigger for learning, student collaboration, teacher facilitation, and increased self-directed learning [12].

Although the inquiry approach is championed in many post-secondary science programs, characterization of the attributes of inquiry has proven difficult. This may in part be due to the fact that the term is used to describe both a teaching and learning approach as well as a process of investigation $[13,14]$.

An inquiry scale, derived from an analysis of nearly 400 undergraduate experiments in 22 lab manuals, was recently introduced by Buck and colleagues [14]. They posited that inquiry is a continuum. Within this continuum they defined five levels, each with a different amount of student independence. As the amount of independence increases, the amount of information provided by the instructor decreases. Our focus is on guided and open inquiry. Guided inquiry provides the research question and procedures, and the students are expected to analyze and explain their results. Open inquiry provides the research question and it is up to the students to design and execute the experiment, interpret the data, and draw conclusions.

The purpose of this paper is to provide an evidencebased description of student behaviors in two types of inquiry experiments that are part of a second-year undergraduate physics laboratory. In one experiment a detailed procedure was given, while the other experiment provided the same apparatus and experimental questions, but asked students to develop their own procedure through written prompts. We followed the inquiry scale defined by Buck [14] and, although not an exact match, the closest levels of inquiry are guided and open inquiry, respectively. The guided-inquiry experiment relied heavily on a lab manual for procedures and analysis. The open-inquiry experiment focused on experimental design. While it included the problem with the onus on students to establish procedures and generate explanations of their data, prompts in the lab manual were used to scaffold student learning. Both experiments focused on process rather than product and engaged students in the stages of design, experimentation, and analysis, with varying levels of support.

We begin by describing the course context for the guided- and open-inquiry experiments. The methodology section outlines the research approach and methods for qualitative data collection and analysis. The results discuss the major themes that capture student behavior during guided- and open-inquiry experiments. The discussion section compares the different student behaviors during the two experiment types. Finally, we offer considerations for the design of physics experiments based on our findings.

\section{COURSE CONTEXT}

The second-year undergraduate physics laboratory at Queen's University comprises eleven experiments whose subject matter overlaps the syllabus of the second-year lecture courses: electromagnetism, waves and vibrations, modern physics, and dynamics.

The first three weeks of the twelve-week semester are devoted to tutorial laboratories that each cover a specific AAPT learning outcome [1] shown in parenthesis: keeping a laboratory record in a Jupyter Notebook [15] (practical laboratory skills), calculating experimental uncertainties using Python and the QExPy Python package [16] (analyzing data), making measurements with an oscilloscope (technical laboratory skills) and the creation of reports using LaTeX and Overleaf (communicating physics). In the remaining nine weeks the students have to complete six experiments and they do that in groups of two. In each three-week period, the groups perform two experiments and, in one of the weeks, they analyze their results or repeat measurements.

The lab manuals inherited from previous instructors were well written and contained step-by-step procedures in recipelike [1,17] format. Using the scheme introduced above, we would classify them as guided-inquiry experiments [14].

As part of a TRESTLE (a multi-institution consortium funded by the National Science Foundation) intervention [18] and laboratory-redesign project that took place between 2016 and 2019, two of the experiments were redesigned and a new experiment on coupled oscillators was designed and implemented. All three experiments required the students to practice open inquiry. Although the experimental task was still defined by the instructor, the students were required to design their own procedures.

The experiments selected for redesign were Young's modulus and compact disk (CD) diffraction. In the Young's modulus experiment, the students measured the Young's modulus of steel using both a static and a dynamic method. The CD diffraction experiment, which is the focus of this paper, was introduced to the second-year laboratory course by author A. M., circa 1993. The original version of this experiment was based on a short paper by Kettler [19]. Students were given a helium-neon laser, a CD, and a copy of Kettler's paper containing the grating equation. They were asked to estimate the grating spacing (also called line spacing) of the $\mathrm{CD}$ as precisely as possible using their own procedures. Consequently, in its original form, this was an open-inquiry experiment. In subsequent years, other instructors had extended the scope of the experiment by asking the students to use their estimate of the grating 
spacing to estimate the wavelength of a second laser, and the lab manual had become more guided.

Reconceptualizing guided-inquiry experiments as openinquiry experiments can, in some cases, involve relatively minor modifications to the lab manual. Frequently, detailed procedural instructions are replaced with a request for the students to design their own strategy or to evaluate a number of different strategies and choose one. The apparatus, of course, is configured to support at least one experimental strategy and the configuration conveys information about how the instructor expects the experiment to be done. Consequently, we found it necessary to add degrees of freedom (d.o.f.) to support open inquiry. For example, in the $\mathrm{CD}$ diffraction experiment it is now possible for students to change the distance between the $\mathrm{CD}$ and the wall where the diffraction pattern is measured, rotate the $\mathrm{CD}$, rotate the laser, and also use a laser with a different wavelength. To avoid overwhelming the students with choices, the lab manual describes the options that are available and the instructor and teaching assistant can help the students make informed choices.

From the instructor's perspective, the following differences between the guided- and open-inquiry student behaviors have been noted: (i) Students performing openinquiry experiments devote time at the beginning of the laboratory period to the design of the experiment and, consequently, they start taking measurements later than those performing guided-inquiry experiments. However, both groups finish the experiment during the three-hour laboratory period. (ii) In students' reports who perform open-inquiry experiments, after reflecting on different procedural approaches, they do suggest how the apparatus might be improved. In some cases we have been able to implement these suggestions. (iii) When students are given apparatus with multiple d.o.f. they occasionally design experiments which combine d.o.f. in ways that were not necessarily anticipated by the instructor. (iv) We found that when students are given the choice of selecting an experiment for a final or culminating report (data from the 2019 session), the open-inquiry experiments are selected, on average, more frequently than the other experiments.

\section{METHODOLOGY}

After redesigning the $\mathrm{CD}$ diffraction experiment, we had two different lab manuals at our disposal. We have included them in the Supplemental Material [20]. Although they shared the same experimental goals, and had the same introduction and theory sections, they embodied different levels of student inquiry. The lab manual for the guidedinquiry experiment had a recipelike procedure with stepby-step instructions. In contrast, the lab manual for the open-inquiry experiment contained a section called "design activities" with prompts asking students to design their own activities. Table I compares the experimental sections and the corresponding learning outcomes for the guided- and open-inquiry experiments.

These manuals were used in the following fashion in the second-year laboratory course in the winter semester of 2017. Eight groups of students (in pairs) performed the open-inquiry experiment in the middle of the semester and another five groups (in pairs) performed the guided-inquiry experiment towards the end of the semester. We designed this study this way so that the students who did the openinquiry experiment did not have access to the guidedinquiry lab manual. Each group was given three hours to complete the experiment. Ethics approval was obtained for the study and student consent was acquired for audiorecording their conversations during the experiment.

On average, it took $2 \mathrm{~h} 5 \mathrm{~min}$ for a group to complete the guided-inquiry experiment, while it took $2 \mathrm{~h} 21 \mathrm{~min}$ for a group to complete the open-inquiry experiment. The audio data files were transcribed using a commercial software called Transcribe [21] by two senior physics undergraduate research assistants with previous transcribing experiences. The two students in all groups were anonymous and identified as Student A and Student B in the transcripts. The transcribers made sure that they were familiar with the students' voices in their randomly assigned audio files before they started transcribing. Each conversation was stamped with a time corresponding to the start of the audio file. A quality assurance check of the transcripts revealed their high accuracy in reflecting the audio recordings.

This paper focuses on the qualitative analysis of the transcripts by addressing the following research question: How do student behaviors compare in experiments that allow for either guided or open inquiry?

Thematic analysis, using the coding procedure described by Corbin and Strauss [22], was carried out to analyze the audio transcripts using a general inductive approach [23]. General inductive analysis refers to an approach that primarily uses reading of data to derive emergent themes through interpretations of the data made by the researcher. Inductive analysis can also be described as bottom-up analysis, where generalizations are built up from initial observations. Conversely, deductive analysis can be described as top-down analysis, where existing high-level generalizations are tested and confirmed. Typically, deductive approaches apply existing theoretical frameworks to data; however, since we found no existing framework on which to guide our analysis, we chose an inductive approach to build a data-driven understanding of the student behavior. Strategies used in this approach include questioning what core meanings are evident in the text in relation to the research question through a process simply described as reading and labelling segments of the text, then grouping labels. The coding procedure we used involved open, axial, and selective coding steps. Open coding involves identifying phrases within text and labeling them as codes. The high number of codes are then grouped 
TABLE I. Comparison of guided- and open-inquiry manuals and learning outcomes for the CD diffraction experiment. Students are provided with recipelike procedures in the guided-inquiry manual while they are prompted to design some of the experimental activities themselves in the open-inquiry manual.

\begin{tabular}{|c|c|c|c|}
\hline \multicolumn{2}{|c|}{ Guided-inquiry experiment } & \multicolumn{2}{|c|}{ Open-inquiry experiment } \\
\hline Manual & Learning outcomes & Manual & Learning outcomes \\
\hline $\begin{array}{l}\text { Make sure that the CD is } \\
\text { parallel to the wall and the } \\
\text { green laser is perpendicular } \\
\text { to the CD; the laser light } \\
\text { will be reflected off the CD } \\
\text { back into the laser. }\end{array}$ & $\begin{array}{l}\text { Students will align the } \\
\text { experimental setup by } \\
\text { following instructions. }\end{array}$ & $\begin{array}{l}\text { Measure all the physical } \\
\text { quantities you need to } \\
\text { predict what the diffraction } \\
\text { pattern should look like } \\
\text { with the CD in the vertical } \\
\text { geometry and the laser light } \\
\text { incident horizontally. }\end{array}$ & $\begin{array}{l}\text { Students will decide what } \\
\text { physical properties to } \\
\text { measure, make the } \\
\text { measurements, and use the } \\
\text { results to predict where the } \\
\text { diffracted light will } \\
\text { intercept the wall. }\end{array}$ \\
\hline $\begin{array}{l}\text { Measure the distance from the } \\
\text { CD to the wall. Measure the } \\
1 \text { st and 2nd order } \\
\text { diffraction spots. }\end{array}$ & $\begin{array}{l}\text { Students will make accurate } \\
\text { measurements of physical } \\
\text { quantities. }\end{array}$ & $\begin{array}{l}\text { Establish procedures for } \\
\text { ensuring that the CD is } \\
\text { parallel to the wall and the } \\
\text { laser light is horizontal. } \\
\text { Measure the diffraction } \\
\text { pattern. }\end{array}$ & $\begin{array}{l}\text { Students will design } \\
\text { experimental procedures to } \\
\text { align the apparatus, decide } \\
\text { what quantities to measure, } \\
\text { and make the } \\
\text { measurements. }\end{array}$ \\
\hline Calculate line spacing $d$. & $\begin{array}{l}\text { Students will calculate } d \text { using } \\
\text { experimental data. }\end{array}$ & $\begin{array}{l}\text { Calculate } d \text { and the } \\
\text { experimental uncertainty } \\
\text { for this single } \\
\text { measurement. }\end{array}$ & $\begin{array}{l}\text { Students will calculate } d \text { and } \\
\text { uncertainties using } \\
\text { experimental data. }\end{array}$ \\
\hline $\begin{array}{l}\text { Rotate the CD to a few } \\
\text { different angles and make } \\
\text { measurements of the } \\
\text { diffracted beams. Replace } \\
\text { with red laser and acquire } \\
\text { more data points. }\end{array}$ & $\begin{array}{l}\text { Students will make use of } \\
\text { different apparatus and } \\
\text { adjust them to make } \\
\text { measurements and compare } \\
\text { results. }\end{array}$ & $\begin{array}{l}\text { Draft a plan that will allow } \\
\text { you to find } d \text { with higher } \\
\text { precision. Identify the } \\
\text { physical quantities you will } \\
\text { measure, think about how } \\
\text { you will measure them, and } \\
\text { carry out your plan. }\end{array}$ & $\begin{array}{l}\text { Students will reflect on their } \\
\text { initial results, design a } \\
\text { procedure that will } \\
\text { minimize the experimental } \\
\text { uncertainties, and carry out } \\
\text { their procedure. }\end{array}$ \\
\hline $\begin{array}{l}\text { Use the re-arranged grating } \\
\text { equation to plot the data and } \\
\text { fit for } d \text {. Calculate the } \\
\text { uncertainty in your } \\
\text { estimate. }\end{array}$ & $\begin{array}{l}\text { Students will use curve fitting } \\
\text { to improve their } \\
\text { experimental results and } \\
\text { uncertainties. }\end{array}$ & $\begin{array}{l}\text { Make use of all your data } \\
\text { points to calculate } d \text { and } \\
\text { your experimental } \\
\text { uncertainty. Can you } \\
\text { identify any assumptions } \\
\text { you have made that might } \\
\text { produce systematic } \\
\text { uncertainties in your result? }\end{array}$ & $\begin{array}{l}\text { Students will evaluate the } \\
\text { systematic uncertainties of } \\
\text { their experimental design. }\end{array}$ \\
\hline
\end{tabular}

into a fewer number of categories in the axial coding phase. The category is named to appropriately represent the group of similar codes it contains. Finally, the selective coding step is completed by further reducing the number of categories into major themes, which are named to appropriately represent the categories each theme contains. The themes addressing the research question are the findings of the study. Emergent themes have been identified from data of each of the guided-and open-inquiry experiments and can be compared to one another to reveal similarities and differences in student behavior. These themes, compared to the intended physics laboratory learning outcomes, provide an illustration of what influence the two different experiments have on student learning.

The guided- and open-inquiry experiment transcripts were analyzed separately, that is, the analysis processes for one set of experimental data was kept distinct from the other, in an effort to reduce bias during the coding process.
Before analysis began, we kept bracketing notes for awareness of personal biases and research biases. Being aware of what we hoped to find through the analysis and, more importantly, setting those biases aside, was important to not influence the inductive coding procedure and to obtain the most true representation of the data and thus the students' behavior.

We analyzed the guided-inquiry transcripts first. L. M. independently completed the open coding of the first guided-inquiry transcript while B.C. independently completed the open coding of the first $15 \mathrm{~min}$ of the same transcript. We compared and discussed our codes. L. M. wrote a description for all the open codes to ensure an accurate understanding of the data and to ensure future transcripts would be approached with a thoroughly developed initial set of codes. B.C. adopted L. M.'s open codes, continued coding part of the first guided-inquiry transcript, compared with L. M.'s, and discussed the differences until 
$100 \%$ agreement was reached. This process continued until coding of the first guided-inquiry transcript from the two coders was completely agreed upon. L. M. then coded the 4 remaining guided-inquiry transcripts. New codes were generated and a few existing codes were modified when necessary. The same coding process was followed for the 8 open-inquiry transcripts.

Axial and selective coding to identify categories and themes for the guided- and then open-inquiry transcripts followed the initial coding phase.

\section{RESULTS}

We report our findings in two sections under qualitative and quantitative results. Qualitative data analysis revealed the major themes associated with student behavior during the laboratory experience. Quantitative data analysis captured the number of categories, codes, and references in each of the themes in the guided- and open-inquiry experiments. Comparisons between these themes are presented in the discussion section.

\section{A. Qualitative analysis results}

Table II depicts qualitative coding analysis results. Shown separately are the guided-inquiry data set and the open-inquiry data set with emergent themes and the categories that comprise each theme.

\section{Guided inquiry}

Four major themes emerged from the qualitative analysis of the guided-inquiry data: (i) Carrying out the experiment; (ii) interpersonal learning; (iii) sense making; and (iv) emotions and attitudes.

"Carrying out the experiment" is intended to represent student behaviors while progressing through the steps prescribed by the lab manual until the end is reached. Student behaviors included constructing apparatus; making predictions, measurements, calculations, and visual observations; and engaging in problem solving and project management. We point to the nature of students' progression through steps in the guided-inquiry experiment, which was found to be oriented toward reaching the end of the lab manual. Audio recordings from the laboratories include, for example, while students took measurements:

Alright do one more, I want to get out of here.

In a similar spirit,

I don't like the [labs] that make you do the lab in the lab.

TABLE II. Themes and categories that emerged from qualitative coding analysis of the guided-inquiry data set and the open-inquiry data set.

\begin{tabular}{|c|c|c|c|}
\hline \multicolumn{2}{|c|}{ Guided-inquiry experiment } & \multicolumn{2}{|c|}{ Open-inquiry experiment } \\
\hline Theme & Category & Theme & Category \\
\hline Carrying out the experiment & $\begin{array}{l}\text { Constructing apparatus } \\
\text { Making predictions } \\
\text { Measurement and calculation } \\
\text { Problem solving } \\
\text { Project management } \\
\text { Visual observation }\end{array}$ & $\begin{array}{l}\text { Experimental process and } \\
\text { components }\end{array}$ & $\begin{array}{l}\text { Process } \\
\text { Measurement and analysis }\end{array}$ \\
\hline Interpersonal learning & $\begin{array}{l}\text { Needing help } \\
\text { Physics language } \\
\text { Peer interaction } \\
\text { Student interaction with instructor } \\
\text { Instructor interaction with students }\end{array}$ & $\begin{array}{l}\text { Self and interpersonal } \\
\text { interactions }\end{array}$ & $\begin{array}{l}\text { Attitude } \\
\text { Interpersonal interactions }\end{array}$ \\
\hline Sense making & $\begin{array}{l}\text { Application } \\
\text { Confirmation } \\
\text { Learning } \\
\text { Question asking } \\
\text { Making meaning } \\
\text { Sense making strategies } \\
\text { Sense making of calculations or } \\
\text { measurements, instructions, } \\
\text { observations, peer's ideas or } \\
\text { suggestions, the task, and } \\
\text { physics concepts }\end{array}$ & Comprehension & $\begin{array}{l}\text { Learning } \\
\text { Question asking } \\
\text { Sense making }\end{array}$ \\
\hline Emotions and attitudes & $\begin{array}{l}\text { Reactions } \\
\text { Marveling } \\
\text { Emotions }\end{array}$ & Experimental design & $\begin{array}{l}\text { Critical thinking } \\
\text { Design }\end{array}$ \\
\hline
\end{tabular}


Other students showed recognition of the value of laboratory time, but remained focused on executing the bareminimum steps:

As much as I'd love to get home we should at least make sure our measurements are kind of precise before we [leave].

Progressing from step to step, students continually refer to the lab manual for direction:

Let's see what we have to do next,

and

Alright, repeat with the other laser.

"Interpersonal learning" represents student behavior learning from and with others, including their laboratory partner, other groups, and the instructor or teaching assistant. Student behaviors related to interpersonal learning included needing help, using physics language, and a host of specific peer interaction modes (e.g., directing, suggesting, informing, and cooperation). Student learning from and with others is exemplified in the way that a student's peers and instructors provided a source for their learning. Learning what $n$ is ( $n$ is the $n$th order diffraction and $\lambda$ is the wavelength of the laser light), in this conversation:

A: $n \lambda$ divided by sine of the $\theta$.

$B$ : What's $n$ ?

A: $n$ is just our number, like diffraction grating when ... it's one.

B: So one $\lambda$ ?

A: Yeah.

B: Oh okay.

In another example, reconciling understanding of measurements:

A: And then we're measuring $N_{1}$ and $N_{2}$, and that's the difference that is going to give us the $Y$.

$B$ : I think you're thinking about measuring $L$, like the distance to the horizontal. We did that once. But the distance to this point is going to change every time we change the angle right?

"Sense making" represents student behavior rationalizing, figuring out, or giving meaning to the task at hand. Students made sense of calculations or measurements, instructions, observations, physics concepts, their peer's ideas or suggestions, and of the task they were given. Application of knowledge gained at another time or place occurred as part of the sense making, as did behaviors of confirmation, asking questions, and using other sense making strategies. Other sense making strategies used by students in the guided-inquiry experiment included asking the instructor or teaching assistant for assistance, looking at the diagram in the lab manual, or drawing a diagram themselves. For example,

I feel like I'd prefer to draw this ... I just think better on paper I guess, I just have to look at the picture really quick.

"Emotions and attitudes" represents students' feelings, emotions, moods, and attitudes related to the laboratory experience. Specifically, this theme includes student reactions, marveling, positive emotions such as confidence, determination, excited, hopeful, and having fun, and negative emotions such as careless, confusion, frustration, disappointment, sarcasm, self-doubt, and stress. Students' expressions of confusion, for example, relate to their understanding of variables:

I understand what they're asking us to do with this equation but I don't understand how, how our $n$ value is supposed to change,

and

I'm still confused about which one is the, like, zero order.

On the opposite side of the emotions, students felt confident in following the procedure:

Well I'm pretty confident in our procedure so I guess we can just take these measurements pretty quick.

As demonstrated by the range of aspects that were part of the students' affective experience, students completing the guided-inquiry experiment communicated a breadth of emotions.

\section{Open inquiry}

Four major themes emerged from the qualitative analysis of the open-inquiry data: (i) Experimental process and components; (ii) self and interpersonal interactions; (iii) comprehension; and (iv) experimental design.

"Experimental process and components" represents student behavior working in a non-stepwise process of experimentation in the open-inquiry experiment. The nature of this experimental process and its components for students was task oriented, meaning that they were given the task to achieve accurate measurements and their behaviors were oriented toward accomplishing the task. The nature of this process in the open-inquiry experiment did not resemble sequential completion of steps, or an end-oriented experience. The process included student 
behaviors related to measurement and analysis and the overall process, which was categorized by the following: configuring laboratory station, observations, being off task, recording activity, referring to resources, safety, and troubleshooting. With this nature of experimental process and components, students accomplished the task they were given in the open-inquiry experiment. Students were interpreting their measurements:

I feel like this is going to be worse of a reading or even greater experimental error on our part,

and

Got a perfect range of values.

Students also considered how to graph the data they gathered:

I'm trying to think of all the things we could plot,

and

I was trying to calibrate that, some sort of relationship where $d$ was the slope of something.

"Self and interpersonal interactions" are those that relate to students' own attitudes and their interactions with others. The aspects of student behaviors that relate to attitude include identity, interest, marveling, and wanting to finish the experiment. The aspects of student behaviors that relate to interpersonal interactions include those with other groups, the instructor or teaching assistant, and their peers. Students had a certain positionality or frame of attitude in the open-inquiry experiment; for example, only one student remarked on wanting to finish the experiment, while other students marveled, making comments such as

Whoa, what are you guys doing? That looks so cool.

Another student, reflecting on their experience of the experiment, remarked that their group were

such scientists.

Students' interactions with the instructor or teaching assistant varied from asking questions, asking for help, and explaining their design. When the instructor approached the students, interactions included explaining concepts or the purpose of the experiment, checking in, answering questions, encouragement, guidance, and prompting. Interaction with other groups involved comparison or gaining understanding from them. Interactions within the laboratory groups ranged widely and included these behaviors: clarification, informing, dismissing, suggesting, showing peer, planning, reassurance, and others related to language and cooperation.

"Comprehension" represents student behavior of coming to understand the task at hand that is related to students' comprehension or understanding that occurred via learning, question asking, and sense making. An example is

Oh wow that was so ... now I understand what's going on. Took me, like, the first hour to figure out what we were, like, the theory behind all of this stuff. Once I understood ...

Such student behaviors included reflection on the experiment design or process. For example,

A: We can just start trying things and then see, but I feel like ...

B: I feel like the original method we did was pretty good.

Questions that students asked ranged in nature, from calculation and measurement questions to design questions and next steps questions. Other types included questions related to data collection, using equipment, observations, and understanding. Understanding question examples include

How do lasers work?

How does this give us the average of $d$ ?

and

Is the ... how is the ... line spacing directly proportional to the distance between the diffraction lines?

Design question examples include

Okay, so what can we change?

Why does it even have to be level, what difference does it make?

and

How did we know that this is going to hit here and then go directly to the center, like it hit the center of this $C D$ ?

Sense making included topics similar to those that students asked questions about, such as calculations, data, measurements, observations, and instructions. However, students also made sense of diagrams, equations, tasks, and the apparatus.

"Experimental design" represents the students' intentional consideration, creation, and execution of plans in the open-inquiry experiment. These behaviors were grouped into two categories: critical thinking and design. Critical thinking behaviors are exemplified by comments such as 
Okay, so. Rotating the CD, how does that affect ... that affects $\theta$ too, right? So let's try this out,

and

If you look at this, the laser light is pointing almost right back into the laser itself, right? So that would indicate, if this is already level, then that should be.

Student design behaviors were further grouped into two categories: constructing apparatus and designing experiment. Constructing apparatus involved making assumptions, being resourceful, concern, designing the apparatus, making adjustments, trial, and using equipment. Designing experiment involved a variety of design-oriented behaviors, including foreseeing issues, decision-making, changing directions, improvement ideas, making predictions, interpreting, and testing these, and identifying tasks, a goal or purpose, and known and unknown information. The following quotation broadly exemplifies the open-inquiry student behaviors of designing the experiment:

So I'm thinking we can ... do several different trials by using different distance from the mirror to the wall.

\section{B. Quantitative analysis results}

We quantified the codes, categories, and themes for each of the guided- and open-inquiry data sets to broadly represent the analysis results. Tables III and IV show the number of categories, codes, and references in each of the themes in the guided- and open-inquiry experiments.

As for the remaining quantitative analysis results, we have created plots to depict the frequencies of themes, categories, and codes for both the guided- and open-inquiry experiments. Figure 1 shows the frequency of each theme based on the average number of references (coded segments of raw text) contributing to it, calculated by dividing the total number of references across all the codes in the theme by the number of the corresponding data sets in the guided- or open-inquiry experiment.

TABLE III. The number of categories, codes, and references in each of the themes in the guided-inquiry experiment. Note that there are 5 guided-inquiry data sets from the 5 groups of students who did the guided-inquiry experiment.

\begin{tabular}{lccc}
\hline \hline Guided-inquiry theme & $\begin{array}{c}\text { No. } \\
\text { Categories }\end{array}$ & $\begin{array}{c}\text { No. } \\
\text { Codes }\end{array}$ & $\begin{array}{c}\text { No. } \\
\text { References }\end{array}$ \\
\hline Carrying out the & 6 & 39 & 890 \\
$\quad$ experiment & 5 & 23 & 553 \\
Interpersonal learning & 12 & 21 & 395 \\
Sense making & 3 & 16 & 130 \\
Emotions and attitudes & 26 & 99 & 1968 \\
Total for guided inquiry & &
\end{tabular}

TABLE IV. The number of categories, codes, and references in each of the themes in the open-inquiry experiment. Note that there are 8 open-inquiry data sets from the 8 groups of students who did the open-inquiry experiment.

\begin{tabular}{lccc}
\hline \hline $\begin{array}{l}\text { Open-inquiry theme } \\
\text { Categories }\end{array}$ & $\begin{array}{c}\text { No. } \\
\text { Codes }\end{array}$ & $\begin{array}{c}\text { No. } \\
\text { References }\end{array}$ \\
\hline $\begin{array}{l}\text { Experimental process and } \\
\quad \text { components }\end{array}$ & 2 & 32 & 708 \\
$\begin{array}{l}\text { Self and interpersonal } \\
\quad \text { interactions }\end{array}$ & 2 & 31 & 366 \\
$\begin{array}{l}\text { Comprehension } \\
\text { Experimental design }\end{array}$ & 3 & 26 & 353 \\
Total for open inquiry & 2 & 23 & 444 \\
\hline \hline
\end{tabular}

Figure 2 shows in more detail all the categories and codes in each theme with the frequency of the corresponding theme, category, and code represented by the area of the circle. To interpret the relative frequency at the level of codes, for example, readers can compare the areas of red circles. In an effort to ensure the figure's readability, we provide an example: "Asking for help," a code within the category "peer interaction" and the interpersonal learning theme, is the smallest red circle among its fellow red circles. This means that asking for help was least frequently coded for during analysis in comparison to other codes in this category. Continuing with the example, "deliberation," seen to the left of asking for help, was more frequently coded for.

By depicting the qualitative analysis in terms of frequency of codes, we are able to visually represent the student behaviors in each of the guided- and open-inquiry

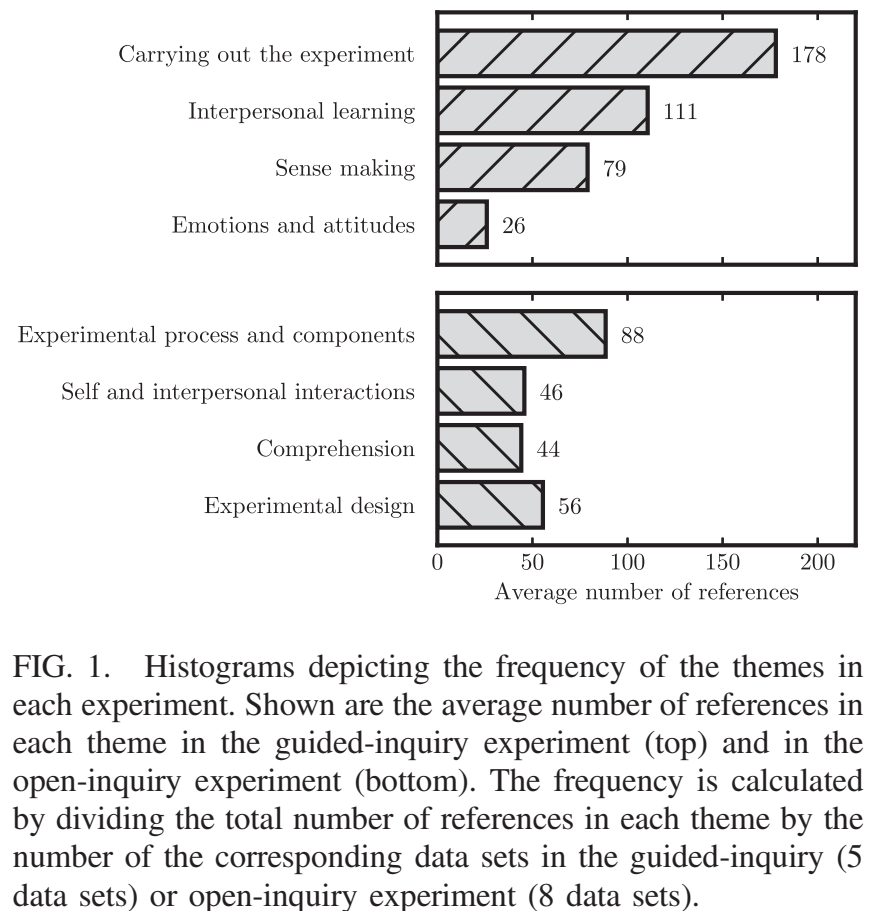
data sets) or open-inquiry experiment (8 data sets). 

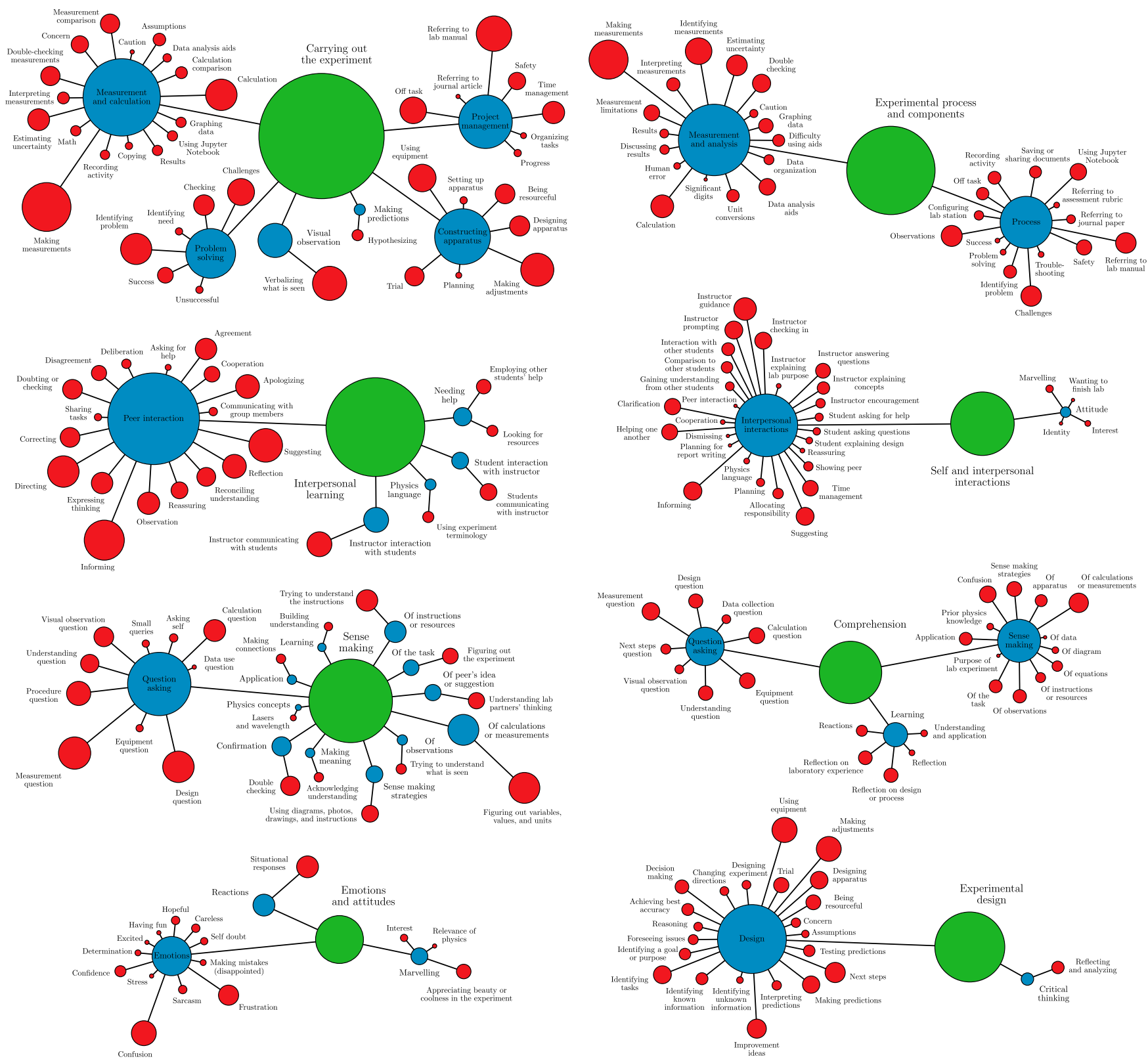

FIG. 2. The complete picture of our qualitative and quantitative analysis results. All categories and codes in each theme are shown for the guided-inquiry experiment (left) and for the open-inquiry experiment (right). The area of each node scales with the frequency of the theme (green), category (blue), and code (red).

experiments. In the guided-inquiry experiment, student behaviors were most frequently coded as carrying out the experiment, within which students most frequently engaged in measurement and calculation, and to lesser frequencies in constructing apparatus, project management, and problem solving. The second highest frequency theme is interpersonal learning, with the highest frequency category being peer interaction, followed by other similarly lower frequency categories such as instructor interaction with students, student interaction with instructor, needing help, and physics language. The third highest frequency theme is sense making, with its highest frequency category question asking, and lower frequency categories including sense making of calculations or measurements, of instructions, and using sense making strategies. The least frequent theme in the guided-inquiry experiment is emotions and attitudes, with the high-frequency category being emotions (including a variety of types such as confusion, frustration, and confidence) and the lower frequency category being marveling. 
In the open-inquiry experiment, student behaviors were most frequently coded as experimental process and components, within which students most frequently engaged in measurement and analysis and less frequently in process, which includes frequent behaviors such as referring to the lab manual, challenges, and observations. The second highest frequency theme is experimental design, with the highest frequency category being design. Design includes a variety of student behaviors, most frequent of which include using equipment, making adjustments, next steps, and improvement ideas. The only other category in this theme is critical thinking. The third highest frequency theme is self and interpersonal interactions. The higher frequency category in this theme is interpersonal interactions, which includes numerous related behaviors such as instructor interacting with students, student interaction with other groups, and student informing (peers). The least frequent theme in the open-inquiry experiment is comprehension, within which students most frequently engaged with sense making, and to lesser frequencies in question asking and learning.

\section{DISCUSSION}

Overall, the guided- and open-inquiry experiments each revealed four different themes, which allowed us to understand student behaviors in each of these experiments as unique. The extent to which and how the nature of student behaviors differed was challenging to capture. In an attempt to illuminate the differences of student behaviors between the two forms of inquiry, we discuss how the themes compare between the experiments, including discussions about common and unique codes in each experiment.

\section{A. Common codes across themes}

We examine the common codes that emerged in both guided- and open-inquiry experiments in this section, i.e., those that represent a specific student behavior that occurred in both data sets. We explore interpretations of such results as a means to address how student behaviors compare in the guided- and open-inquiry experiments; this is our research question. The common codes emerged in both experiments as expected since (a) the students did the CD diffraction experiment with the same set of provided apparatus; (b) there are common learning outcomes shared within the two levels of inquiry for this experiment as seen in Table I. We list in detail these common codes in Table V in the Appendix with their frequencies of being referenced in the corresponding themes in the two levels of inquiry.

Most of the common codes emerged in the carry out the experiment theme in the guided-inquiry experiment, which is also the theme that has the largest number of codes and references. These common codes are either in the experimental process and components or the experimental design theme in the open-inquiry experiment, except that the "planning" and "time management" codes are in the self and interpersonal interactions theme. Some of these common codes have similar frequencies in the two experiments while many have large differences in frequencies. For example, students made similar amount of efforts in "being resourceful," "designing apparatus," making "trial," "using equipment," and "double checking measurements" in the two experiments, and often talked about "safety." Notably, students did a lot more "making adjustments," "calculation," "estimating uncertainty," "making measurements," "identifying problem," and "referring to lab manual" throughout the guided-inquiry experiment compared to the open-inquiry experiment. They also encountered more "challenges" and went "off task" a lot more often. On the other hand, students in the open-inquiry experiment did more "using Jupyter Notebook" and used "data analysis aids" more often than those in the guidedinquiry experiment.

Some common codes emerged both in the interpersonal learning theme in guided inquiry and in the self and interpersonal interactions theme in open inquiry. Student conversations in guided inquiry were most often "informing" and "suggesting" ideas to each other. The natures of the conversations in open inquiry were quite different and were often more design based. Therefore many of the conversations moved away from simply informing or suggesting and fell into the unique codes in the design category in the experimental design theme, discussed in the next section.

We also saw that students in guided inquiry had more questions (a total of 227 references in 5 data sets) than those in open inquiry (a total of 133 references in 8 data sets). The common codes in the sense making theme in guided inquiry that are more frequent than those in the comprehension theme in open inquiry are "calculation question," "design question," "measurement question," and "visual observation question." On the other hand, the "equipment question" code was much more frequent in open inquiry.

Lastly, the "confusion" code emerged much more frequently in the emotions and attitudes theme in guided inquiry than in the comprehension theme in open inquiry. There were a total of 35 references of confusion in the 5 guided-inquiry data sets, and 25 references in the 8 openinquiry data sets, indicating that students on average experienced confusion less frequently in the open-inquiry experiment.

\section{B. Unique codes across themes}

Many unique codes emerged in either the guided- or open-inquiry experiment that highlight the differences in these two experiments. We have listed the 59 codes that are unique in the guided-inquiry experiment and the 72 codes that are unique in the open-inquiry experiment in Tables VI-IX in the Appendix. 
There are 12 unique codes in the carrying out the experiment theme in guided inquiry, with the most frequently referenced ones being "measurement comparison," "checking," and "verbalizing what is seen." There are 14 unique codes in the experimental process and components theme in open inquiry and the most frequent ones are "observations," "identifying measurements," and "measurement limitations." Observations include visual observations in the experiment as well as other general observations. Identifying measurements and measurement limitations are unique in open inquiry, which indicates that this experiment successfully prompted the students to think often as well as deeply about the measurements they should make and the experimental limitations of their measurements. We did not see these student behaviors in the guided-inquiry experiment.

There are a total of 18 unique codes in the interpersonal learning theme in guided inquiry, out of which 13 unique codes appeared in the peer interaction category. The interactions in the guided-inquiry experiment were often between the two students performing the experiment and the students were "apologizing" to each other, being in "agreement" with one another, "doubting or checking," "correcting," "directing," "expressing thinking," making "observation," and "reconciling understanding." This is consistent with the students more frequently informing and suggesting to each other in the guided-inquiry experiment, shown in the common codes Table V. There are a total of 24 unique codes in the self and interpersonal interactions theme in open inquiry, out of which 21 unique codes appeared in the interpersonal interactions category. The most frequent ones include "instructor answering questions," "instructor checking in," "instructor guidance," "instructor prompting," and students seeking "clarification" and "helping one another." We saw richer and more indepth interactions in the open-inquiry experiment between the instructor and students, and between students in different groups.

There are 15 unique codes in the sense making theme in guided inquiry including "procedure question" and "understanding lab partners' thinking" shown in Table VII. In open inquiry there are a total of 18 unique codes in the comprehension theme, including "reflection on design or process" and "reflection on laboratory experience" in the learning category. Here is an example of reflection on design or process:

A: Well the other one is still valid though. It's still a valid method, we're just taking the next one, which makes sense why it's not exactly.

B: No no, I feel like, well our $L$ is technically, our $L$ is actually what we wrote as $d$. L, it seems like it's the distance.

And an example of reflection on laboratory experience is
A: It really doesn't seem like it's gonna be very long. B: No [be]cause I think a lot of like the lab is spent like kind of figuring out what to do.

A: Yeah.

B: So then your actual experiment is like if you came back in and knowing exactly what to do.

Finally, there are 14 unique codes in the emotions and attitudes theme in guided inquiry mostly in the "emotions" category. The negative emotions include "careless," "frustrations," "making mistakes (disappointed)," "sarcasm," "self doubt," and "stress." The positive emotions are "confidence," "determination," "excited," "having fun," and "hopeful." The most frequent emotion the students experienced was frustration, for example,

We should have done the green and like the adjusting, then we should have done the red, why didn't they just tell us to do that. You know what I mean?

We did not see any of these emotions in open-inquiry experiment. Instead, we saw 16 unique codes in the experimental design theme including "reflecting and analyzing" and 15 codes in the design category. Students did some "decision making":

Okay so 10 degrees... What should we do, 10? Do something a bit more. Let's do a 5 degree one as well ...

They were "identifying tasks":

A: We need ...

$B:$ Oh the angle measurement, that's the other thing we need.

A: Angle between that and the wall?

$B$ : Well we can do the angle between this and the vertical.

The students were talking about "improvement ideas":

Um maybe it, maybe the red [laser] will be better, or maybe if it was closer [than] we can see.

And "next steps":

We're gonna be able to get a bunch of data. And we're gonna know like for each data point like n, the wavelength, $\sin \theta_{n}$, and $\sin \theta_{0}$, and then that's what's gonna give us $d$.

\section{Mapping onto learning outcomes and AAPT's guidelines}

Our findings are consistent with the intended laboratory learning outcomes we outlined in Table I. Specifically, both the guided- and open-inquiry experiments asked the 
students to align their apparatus, make measurements and calculations, and estimate uncertainties. These learning outcomes are reflected in the common codes that are present in both experiments: making adjustments, using equipment, making measurements, calculation, and estimating uncertainty. In addition, the open-inquiry experiment prompted the students to make predictions, decide what physical quantities to measure, and design experimental procedures. These were reflected in the 27 references in the making predictions code, 64 references in the identifying measurements code, and a total of 249 references in the 16 unique codes in the experimental design theme, respectively.

Furthermore, the AAPT guidelines recommend that students should be able to design a procedure to make a measurement, should have a hands-on opportunity to construct an apparatus, should do basic troubleshooting, should understand the limitations of their experimental design, and reflect on their results and suggest ways to improve their design. We saw in our analysis results that, while the guided-inquiry experiment addressed some of these recommended learning outcomes, the open-inquiry experiment allowed a much deeper and broader coverage of all aspects of these recommendations.

\section{CONCLUSION}

In this study we analyzed audio transcripts of students' conversations that took place while they were performing either a guided-inquiry experiment, in which procedures were provided, or an open-inquiry experiment, in which students were required to design their own procedures. We compared student behaviors for both inquiry levels, by studying the results of qualitative and quantitative analysis of the transcripts, and found many differences.

First, we found that students in the guided-inquiry experiment, with the ultimate goal of completing all the prescribed tasks, focused on following the detailed instructions that were provided as evidenced by their frequent referencing of the lab manual. In contrast, the open-inquiry experiment provided the students with the freedom to explore a range of approaches and design their own experimental procedures.

Second, students in guided inquiry expressed many emotions, often negative ones including frustration and confusion. This was somewhat surprising since the students were given detailed procedures in the lab manual and should know very well what to do in the next steps. We argue that the negative emotions could be correlated with our first finding that the students came into the laboratory with the mindset that they would be able to carry out the experiment by simply following the instructions. When they experienced technical or other unexpected problems, they often reverted to express negative emotions including frustration and confusion. In comparison, students in open inquiry did not express any frustrations and they showed confusion less frequently. These students seemed to have come into the laboratory knowing that the lab manual would not give them all the answers and they were expected to figure out the next steps. With this mindset, these students in general had more positive experiences than those in guided inquiry.

Finally, the students in open inquiry had more opportunities to develop their experimental design skills. Many unique student behaviors emerged in the comprehension and experimental design themes. Although the openinquiry experiment did not ask the students to design all aspects of this experiment, the tasks required the students to develop skills in one of the core AAPT curriculum areas, experimental design. It provided an opportunity for students to configure their apparatus, troubleshoot their apparatus and method, reflect on their results, and evaluate their procedure, and consequently they started to think like a physicist.

The open-inquiry experiment illustrates one of the foundational principles of inquiry-based learning: students build new meaning through a process of active knowledge creation as defined in the theory of constructivism [5]. When students actively direct an investigation, in this case designing an experiment and interpreting its outcomes, they must draw on what they already know about theoretical physics and apply these concepts to the practice of experimental design and analysis. This study captures student constructivist behaviors and illustrates how they were able to unite theory and practice to successfully complete the experiment.

We find that student behavior in physics undergraduate laboratory experiments can be significantly improved by increasing the level of inquiry from guided to open. In some cases, the experimental apparatus does not have to be changed; it is sufficient to replace recipelike procedures with questions or prompts that give students the freedom to design some of the experimental activities themselves. Alternatively, students can be given an experimental problem or task and the apparatus can be configured to accommodate a variety of experimental approaches. Using the analogy from mechanics introduced above, these experiments can be considered to have multiple d.o.f. from which the students have to choose one. In the experiment described here, students had to design a strategy that resulted in the best experimental precision they could achieve, after a consideration of the experimental uncertainties and the available approaches.

The increased level of inquiry promotes AAPT learning outcomes and has the beneficial side-effect of reducing negative affective experiences for students. An important finding being that detailed experimental procedures can, counterintuitively, be the source of the negative affective experiences.

We suggest that when instructors are designing openinquiry laboratory experiments or transforming a guided- 
inquiry experiment into an open-inquiry experiment, they consider whether instructions could be turned into questions or prompts. Rather than telling the students what to do, students can be given the freedom to evaluate a number of experimental options. Clearly, for this to be successful, the apparatus has to support more than one experimental strategy. It is not always necessary to ask the students to design a complete experimental procedure to raise the inquiry level. Nevertheless, the instructor has to find a manageable balance between the amount of detail given in the lab manual and the number of design tasks that the students are required to execute.

This study describes the positive effect of increasing the inquiry level of undergraduate physics experiments on student behavior. Moreover, it provides guidelines on how to best design or redesign undergraduate experiments to support open inquiry, which we have posited as a way of transferring agency from the instructor to the student. However, we do recognize that a study of this sort has limitations that, for completeness, we delineate here: 1 . It was based on a specific experimental topic on CD diffraction; 2 . The students in this study were from a secondyear undergraduate laboratory course in one research institution, therefore may not represent those who are new to universities or more senior in their undergraduate studies; 3 . The students who did the guided- and openinquiry experiments are different and randomly selected from the class, which may not represent a general population; 4. While we categorized our experiments on two specific inquiry levels, we recognize that each experiment remains unique. The design of each experiment must retain some degree of flexibility to support student familiarity with the topic and expertise with a specific experimental process. As a result, the level of instructor guidance, in terms of the number and type of written lab manual and inlab prompts, may shift accordingly.

\section{ACKNOWLEDGMENTS}

This work was funded by the TRESTLE network [18] (NSF DUE1525775); the Department of Physics, Engineering Physics and Astronomy, the Center for Teaching and Learning, and the Faculty of Engineering and Applied Science at Queen's University. We would like to thank C. Knapper, R. Knobel, G. L. McLean, and M. Swarthout for critical readings of this manuscript.

\section{APPENDIX: COMMON AND UNIQUE CODES}

We include the tables of common and unique codes in the guided- and open-inquiry experiments. The common codes represent specific student behaviors that occurred in both data sets, while the unique codes highlight the differences in student behaviors in the two experiments.

TABLE V. A list of the 40 common codes that emerged from qualitative coding analysis of the guided-inquiry data set and the openinquiry data set. We list the 4 themes from the guided-inquiry experiment first, followed by the 4 themes from the open-inquiry experiment. The numbers shown in the table are how many times each code is referenced in the corresponding experiment and how many files each code is referenced (shown in parentheses). Note that the total number of guided- and open-inquiry files is 5 and 8 , respectively.

\begin{tabular}{|c|c|c|c|c|c|c|c|c|}
\hline \multirow[b]{2}{*}{ Code } & \multicolumn{4}{|c|}{ Guided-inquiry experiment } & \multicolumn{4}{|c|}{ Open-inquiry experiment } \\
\hline & $\begin{array}{c}\text { Carrying } \\
\text { out the } \\
\text { experiment }\end{array}$ & $\begin{array}{l}\text { Interpersonal } \\
\text { learning }\end{array}$ & $\begin{array}{l}\text { Sense } \\
\text { making }\end{array}$ & $\begin{array}{l}\text { Emotions } \\
\text { and } \\
\text { attitudes }\end{array}$ & $\begin{array}{l}\text { Experimental } \\
\text { process and } \\
\text { components }\end{array}$ & $\begin{array}{c}\text { Self and } \\
\text { interpersonal } \\
\text { interactions }\end{array}$ & Comprehension & $\begin{array}{c}\text { Experimental } \\
\text { design }\end{array}$ \\
\hline Being resourceful & $22(5)$ & $\ldots$ & $\ldots$ & $\ldots$ & $\ldots$ & $\ldots$ & $\ldots$ & $20(7)$ \\
\hline Designing apparatus & $23(5)$ & $\cdots$ & $\cdots$ & $\cdots$ & $\cdots$ & $\cdots$ & $\ldots$ & $28(6)$ \\
\hline Making adjustments & $62(5)$ & $\cdots$ & $\cdots$ & $\cdots$ & $\cdots$ & $\cdots$ & $\cdots$ & $56(8)$ \\
\hline Planning & $2(2)$ & $\cdots$ & $\cdots$ & $\ldots$ & $\ldots$ & $6(4)$ & $\ldots$ & $\ldots$ \\
\hline Trial & $21(5)$ & $\cdots$ & $\ldots$ & $\cdots$ & $\ldots$ & $\ldots$ & $\ldots$ & $21(7)$ \\
\hline Using equipment & $43(5)$ & $\cdots$ & $\cdots$ & $\cdots$ & $\cdots$ & $\cdots$ & $\cdots$ & $57(8)$ \\
\hline Calculation & $56(4)$ & $\cdots$ & $\cdots$ & $\cdots$ & $47(8)$ & $\cdots$ & $\ldots$ & $\ldots$ \\
\hline Data analysis aids & $4(2)$ & $\cdots$ & $\cdots$ & $\cdots$ & $25(4)$ & $\ldots$ & $\ldots$ & $\cdots$ \\
\hline Graphing data & $6(2)$ & $\cdots$ & $\cdots$ & $\cdots$ & $19(5)$ & $\cdots$ & $\cdots$ & $\cdots$ \\
\hline Assumptions & $9(4)$ & $\cdots$ & $\cdots$ & $\cdots$ & $\ldots$ & $\ldots$ & $\ldots$ & $5(5)$ \\
\hline Caution & $1(1)$ & $\cdots$ & $\cdots$ & $\cdots$ & $6(5)$ & $\cdots$ & $\cdots$ & $\cdots$ \\
\hline Concern & $17(4)$ & $\cdots$ & $\cdots$ & $\cdots$ & $\ldots$ & $\cdots$ & $\ldots$ & $8(6)$ \\
\hline $\begin{array}{c}\text { Double checking } \\
\text { measurements }\end{array}$ & $21(4)$ & $\cdots$ & $\cdots$ & $\cdots$ & $30(7)$ & $\cdots$ & $\cdots$ & $\cdots$ \\
\hline Estimating uncertainty & $27(3)$ & $\cdots$ & $\cdots$ & $\cdots$ & $39(7)$ & $\cdots$ & $\cdots$ & $\cdots$ \\
\hline Interpreting measurements & $8(3)$ & $\cdots$ & $\cdots$ & $\cdots$ & $16(7)$ & $\cdots$ & $\cdots$ & $\cdots$ \\
\hline Making measurements & $135(5)$ & $\cdots$ & $\cdots$ & $\cdots$ & $138(8)$ & $\cdots$ & $\cdots$ & $\cdots$ \\
\hline Recording activity & $5(1)$ & $\cdots$ & $\cdots$ & $\cdots$ & $15(6)$ & $\cdots$ & $\cdots$ & $\cdots$ \\
\hline Using Jupyter Notebook & $6(2)$ & $\cdots$ & $\cdots$ & $\cdots$ & $25(5)$ & $\cdots$ & $\cdots$ & $\cdots$ \\
\hline Results & $6(3)$ & $\ldots$ & $\ldots$ & $\ldots$ & $7(2)$ & $\cdots$ & $\cdots$ & $\cdots$ \\
\hline
\end{tabular}


TABLE V. (Continued)

\begin{tabular}{|c|c|c|c|c|c|c|c|c|}
\hline \multirow[b]{2}{*}{ Code } & \multicolumn{4}{|c|}{ Guided-inquiry experiment } & \multicolumn{4}{|c|}{ Open-inquiry experiment } \\
\hline & $\begin{array}{c}\text { Carrying } \\
\text { out the } \\
\text { experiment }\end{array}$ & $\begin{array}{l}\text { Interpersonal } \\
\text { learning }\end{array}$ & $\begin{array}{l}\text { Sense } \\
\text { making }\end{array}$ & $\begin{array}{c}\text { Emotions } \\
\text { and } \\
\text { attitudes }\end{array}$ & $\begin{array}{l}\text { Experimental } \\
\text { process and } \\
\text { components }\end{array}$ & $\begin{array}{c}\text { Self and } \\
\text { interpersonal } \\
\text { interactions }\end{array}$ & Comprehension & $\begin{array}{c}\text { Experimental } \\
\text { design }\end{array}$ \\
\hline Challenges & $41(5)$ & $\cdots$ & $\cdots$ & $\cdots$ & $38(7)$ & $\cdots$ & $\cdots$ & $\cdots$ \\
\hline Identifying problem & $55(5)$ & $\cdots$ & $\cdots$ & $\cdots$ & $15(6)$ & $\cdots$ & $\cdots$ & $\cdots$ \\
\hline Success & $14(4)$ & $\cdots$ & $\cdots$ & $\cdots$ & $2(2)$ & $\cdots$ & $\cdots$ & $\cdots$ \\
\hline Off task & $40(5)$ & $\cdots$ & $\cdots$ & $\cdots$ & $14(5)$ & $\cdots$ & $\cdots$ & $\cdots$ \\
\hline Referring to journal article & $1(1)$ & $\cdots$ & $\cdots$ & $\cdots$ & $7(3)$ & $\cdots$ & $\cdots$ & $\cdots$ \\
\hline Referring to lab manual & $71(5)$ & $\cdots$ & $\cdots$ & $\cdots$ & $38(7)$ & $\cdots$ & $\cdots$ & $\cdots$ \\
\hline Safety & $17(5)$ & $\cdots$ & $\cdots$ & $\cdots$ & $21(7)$ & $\cdots$ & $\cdots$ & $\cdots$ \\
\hline Time management & $28(4)$ & $\cdots$ & $\cdots$ & $\cdots$ & $\ldots$ & $22(6)$ & $\ldots$ & $\cdots$ \\
\hline Cooperation & $\ldots$ & $14(4)$ & $\cdots$ & $\cdots$ & $\cdots$ & $2(2)$ & $\cdots$ & $\cdots$ \\
\hline Informing & $\cdots$ & $91(5)$ & $\cdots$ & $\cdots$ & $\cdots$ & $30(6)$ & $\cdots$ & $\cdots$ \\
\hline Reassuring & $\cdots$ & $16(4)$ & $\cdots$ & $\cdots$ & $\cdots$ & $2(2)$ & $\cdots$ & $\cdots$ \\
\hline Reflection & $\cdots$ & $32(5)$ & $\cdots$ & $\cdots$ & $\cdots$ & $\cdots$ & $3(2)$ & $\cdots$ \\
\hline Suggesting & $\cdots$ & $64(5)$ & $\ldots$ & $\ldots$ & $\ldots$ & $29(6)$ & $\ldots$ & $\ldots$ \\
\hline Calculation question & $\cdots$ & $\ldots$ & $27(4)$ & $\cdots$ & $\cdots$ & $\ldots$ & $23(6)$ & $\cdots$ \\
\hline Design question & $\cdots$ & $\cdots$ & $56(5)$ & $\cdots$ & $\cdots$ & $\cdots$ & $18(7)$ & $\cdots$ \\
\hline Equipment question & $\cdots$ & $\cdots$ & $3(1)$ & $\cdots$ & $\cdots$ & $\cdots$ & $22(8)$ & $\cdots$ \\
\hline Measurement question & $\cdots$ & $\cdots$ & $59(5)$ & $\cdots$ & $\cdots$ & $\cdots$ & $28(7)$ & $\cdots$ \\
\hline Understanding question & $\ldots$ & $\ldots$ & $19(5)$ & $\cdots$ & $\ldots$ & $\ldots$ & $19(7)$ & $\cdots$ \\
\hline Visual observation question & $\cdots$ & $\cdots$ & $22(5)$ & $\cdots$ & $\cdots$ & $\ldots$ & $7(5)$ & $\cdots$ \\
\hline Interest & $\cdots$ & $\cdots$ & $\cdots$ & $3(2)$ & $\cdots$ & $3(3)$ & $\cdots$ & $\cdots$ \\
\hline Confusion & $\cdots$ & $\cdots$ & $\cdots$ & $35(5)$ & $\cdots$ & $\cdots$ & $25(8)$ & $\cdots$ \\
\hline
\end{tabular}

TABLE VI. Open codes that are unique in the carrying out the experiment theme in the guided-inquiry data set in comparison to the experimental process and components theme in the open-inquiry data set. The numbers shown in the table are how many times each code is referenced in the corresponding experiment and how many files each code is referenced (shown in parentheses). Note that there are a total of 5 guided-inquiry files and 8 open-inquiry files.

\begin{tabular}{|c|c|c|c|c|c|}
\hline \multicolumn{3}{|c|}{ Carrying out the experiment (Guided-inquiry experiment) } & \multicolumn{3}{|c|}{ Experimental process and components (Open-inquiry experiment) } \\
\hline Category & Code & $\begin{array}{c}\text { References } \\
\text { (Files) }\end{array}$ & Category & Code & $\begin{array}{c}\text { References } \\
\text { (Files) }\end{array}$ \\
\hline $\begin{array}{c}\text { Constructing } \\
\text { apparatus }\end{array}$ & Setting up apparatus & $3(3)$ & Process & Configuring lab station & $8(6)$ \\
\hline $\begin{array}{l}\text { Making } \\
\text { predictions }\end{array}$ & Hypothesizing & $7(4)$ & & Observations & $40(8)$ \\
\hline \multirow{4}{*}{$\begin{array}{l}\text { Measurement } \\
\text { and Calculation }\end{array}$} & Calculation comparison & $8(3)$ & & Saving or sharing documents & $13(7)$ \\
\hline & Math & $6(3)$ & & Referring to assessment & $3(2)$ \\
\hline & Measurement comparison & $21(3)$ & & Troubleshooting & $3(3)$ \\
\hline & Coping & $3(2)$ & & Problem solving & $3(2)$ \\
\hline \multirow[t]{3}{*}{ Problem solving } & Checking & $24(4)$ & & Significant digits & $1(1)$ \\
\hline & Identifying need & $3(2)$ & Measurement & Unit conversions & $14(6)$ \\
\hline & Unsuccessful & $3(2)$ & and analysis & Data organization & $9(3)$ \\
\hline \multirow[t]{2}{*}{ Project management } & Organizing tasks & $2(1)$ & & Difficulty using aids & $13(5)$ \\
\hline & Progress & $3(2)$ & & Identifying measurements & $64(8)$ \\
\hline \multirow[t]{3}{*}{ Visual observation } & Verbalizing what is seen & $66(5)$ & & Measurement limitations & $23(7)$ \\
\hline & & & & Discussing results & $8(5)$ \\
\hline & & & & Human error & $4(3)$ \\
\hline
\end{tabular}


TABLE VII. Open codes that are unique in the interpersonal learning theme in the guided-inquiry data set in comparison to the self and interpersonal interactions theme in the open-inquiry data set. The numbers shown in the table are how many times each code is referenced in the corresponding experiment and how many files each code is referenced (shown in parentheses). Note that there are a total of 5 guided-inquiry files and 8 open-inquiry files.

\begin{tabular}{|c|c|c|c|c|c|}
\hline \multicolumn{3}{|c|}{ Interpersonal learning (Guided-inquiry experiment) } & \multicolumn{3}{|c|}{ Self and interpersonal interactions (Open-inquiry experiment) } \\
\hline Category & Code & $\begin{array}{l}\text { References } \\
\text { (Files) }\end{array}$ & Category & Code & $\begin{array}{c}\text { References } \\
\text { (Files) }\end{array}$ \\
\hline \multirow[t]{2}{*}{ Needing help } & Looking for resources & $7(4)$ & Attitude & Identity & $1(1)$ \\
\hline & Employing other students' help & $12(3)$ & & Wanting to finish the lab & $1(1)$ \\
\hline Physics language & Using experiment terminology & $7(3)$ & & Marveling & $5(4)$ \\
\hline \multirow[t]{13}{*}{ Peer interaction } & $\begin{array}{l}\text { Communicating with group } \\
\text { members }\end{array}$ & $1(1)$ & $\begin{array}{l}\text { Interpersonal } \\
\text { interactions }\end{array}$ & Instructor answering questions & $20(6)$ \\
\hline & Apologizing & $32(4)$ & & Instructor checking in & $26(8)$ \\
\hline & Agreement & $26(5)$ & & Instructor encouragement & $8(4)$ \\
\hline & Asking for help & $2(1)$ & & Instructor explaining concepts & $14(7)$ \\
\hline & Deliberation & $5(2)$ & & $\begin{array}{l}\text { Instructor explaining the } \\
\text { purpose of the lab }\end{array}$ & $2(1)$ \\
\hline & Disagreement & $13(3)$ & & Instructor guidance & $46(8)$ \\
\hline & Doubting or checking & $22(4)$ & & Instructor prompting & $29(8)$ \\
\hline & Sharing tasks & $3(2)$ & & Interaction with other students & $15(5)$ \\
\hline & Correcting & $22(5)$ & & Comparison to other students & $12(5)$ \\
\hline & Directing & $56(5)$ & & $\begin{array}{l}\text { Gaining understanding } \\
\text { from other students }\end{array}$ & $7(3)$ \\
\hline & Expressing thinking & $26(5)$ & & Peer interaction & $1(1)$ \\
\hline & Observation & $28(5)$ & & Clarification & $24(8)$ \\
\hline & Reconciling understanding & $20(5)$ & & Helping one another & $23(8)$ \\
\hline $\begin{array}{l}\text { Student interaction } \\
\text { with instructor }\end{array}$ & $\begin{array}{l}\text { Student communicating with } \\
\text { instructor }\end{array}$ & $16(4)$ & & Dismissing & $1(1)$ \\
\hline \multirow{7}{*}{$\begin{array}{l}\text { Instructor interaction } \\
\text { with students }\end{array}$} & Instructor communicating with & $35(5)$ & & Allocating responsibility & $10(5)$ \\
\hline & students & & & Physics language & $3(3)$ \\
\hline & & & & Planning for report writing & $1(1)$ \\
\hline & & & & Showing peer & $8(5)$ \\
\hline & & & & Student asking for help & $6(5)$ \\
\hline & & & & Student asking questions & $5(4)$ \\
\hline & & & & Student explaining design & $4(2)$ \\
\hline
\end{tabular}


TABLE VIII. Open codes that are unique in the sense making theme in the guided-inquiry data set in comparison to the comprehension theme in the open-inquiry data set. The numbers shown in the table are how many times each code is referenced in the corresponding experiment and how many files each code is referenced (shown in parentheses). Note that there are a total of 5 guidedinquiry files and 8 open-inquiry files.

\begin{tabular}{|c|c|c|c|c|c|}
\hline \multicolumn{3}{|c|}{ Sense making (Guided-inquiry experiment) } & \multicolumn{3}{|c|}{ Comprehension (Open-inquiry experiment) } \\
\hline Category & Code & $\begin{array}{l}\text { References } \\
\text { (Files) }\end{array}$ & Category & Code & $\begin{array}{c}\text { References } \\
\text { (Files) }\end{array}$ \\
\hline Learning & Building understanding & $4(3)$ & Learning & Understanding and application & $4(2)$ \\
\hline Application & Making connections & $5(2)$ & & Reflection on design or process & $18(6)$ \\
\hline Confirmation & Double checking & $21(3)$ & & $\begin{array}{l}\text { Reflection on laboratory } \\
\text { experience }\end{array}$ & $17(4)$ \\
\hline \multirow[t]{4}{*}{ Question asking } & Small queries & $3(3)$ & & Reactions & $11(6)$ \\
\hline & Asking self & $4(3)$ & Question asking & Data collection question & $7(4)$ \\
\hline & Data use question & $1(1)$ & & Next steps question & $9(3)$ \\
\hline & Procedure question & $33(5)$ & Sense making & Application & $15(6)$ \\
\hline Making meaning & Acknowledge understanding & $5(2)$ & & Prior physics knowledge & $4(2)$ \\
\hline $\begin{array}{l}\text { Sense making } \\
\text { strategies }\end{array}$ & $\begin{array}{l}\text { Using diagrams, photos, } \\
\text { drawings, and instructions }\end{array}$ & $16(5)$ & & Sense making strategies & $20(7)$ \\
\hline $\begin{array}{l}\text { Of calculations or } \\
\text { measurements }\end{array}$ & $\begin{array}{l}\text { Figuring out variables, } \\
\text { values, and units }\end{array}$ & $54(5)$ & & Of apparatus & $13(6)$ \\
\hline $\begin{array}{l}\text { Of instructions or } \\
\text { resources }\end{array}$ & $\begin{array}{l}\text { Trying to understand the } \\
\text { instructions }\end{array}$ & $26(5)$ & & Of calculations or measurements & $34(8)$ \\
\hline Of observations & $\begin{array}{l}\text { Trying to understand } \\
\text { what is seen }\end{array}$ & $6(3)$ & & Of data & $1(1)$ \\
\hline $\begin{array}{l}\text { Of peer's idea or } \\
\text { suggestion }\end{array}$ & $\begin{array}{l}\text { Understanding lab partners' } \\
\text { thinking }\end{array}$ & $15(5)$ & & Of diagram & $4(3)$ \\
\hline Of the task & Figuring out the experiment & $14(5)$ & & Of equations & $10(4)$ \\
\hline \multirow[t]{4}{*}{ Physics concepts } & Lasers and wavelength & $2(1)$ & & Of instructions or resources & $9(5)$ \\
\hline & & & & Of observations & $16(7)$ \\
\hline & & & & Of the task & $15(7)$ \\
\hline & & & & Purpose of lab experiment & $1(1)$ \\
\hline
\end{tabular}

TABLE IX. Open codes that are unique in the emotions and attitudes theme in the guided-inquiry data set in comparison to the experimental design theme in the open-inquiry data set. The numbers shown in the table are how many times each code is referenced in the corresponding experiment and how many files each code is referenced (shown in parentheses). Note that there are a total of 5 guidedinquiry files and 8 open-inquiry files.

\begin{tabular}{|c|c|c|c|c|c|}
\hline \multicolumn{3}{|c|}{ Emotions and attitudes (Guided-inquiry experiment) } & \multicolumn{3}{|c|}{ Experimental design (Open-inquiry experiment) } \\
\hline Category & Code & $\begin{array}{c}\text { References } \\
\text { (Files) }\end{array}$ & Category & Code & $\begin{array}{c}\text { References } \\
\text { (Files) }\end{array}$ \\
\hline Reactions & Situational responses & $27(5)$ & Critical thinking & Reflecting and analyzing & $14(6)$ \\
\hline \multirow[t]{2}{*}{ Marveling } & $\begin{array}{l}\text { Appreciating beauty or coolness in } \\
\text { the experiment }\end{array}$ & $12(3)$ & Design & Designing experiment & $7(5)$ \\
\hline & Relevance of physics & $1(1)$ & & Changing directions & $7(5)$ \\
\hline \multirow[t]{13}{*}{ Emotions } & Careless & $4(3)$ & & Decision making & $17(5)$ \\
\hline & Frustration & $23(5)$ & & Achieving best accuracy & $13(5)$ \\
\hline & Making mistakes (disappointed) & $2(2)$ & & Reasoning & $7(5)$ \\
\hline & Sarcasm & $4(2)$ & & Foreseeing issues & $9(6)$ \\
\hline & Self doubt & $3(3)$ & & Identifying a goal or purpose & $12(7)$ \\
\hline & Stress & $1(1)$ & & Identifying known information & $13(7)$ \\
\hline & Confidence & $7(3)$ & & Identifying tasks & $29(8)$ \\
\hline & Determination & $2(1)$ & & Identifying unknown information & $4(4)$ \\
\hline & Excited & $1(1)$ & & Improvement ideas & $33(7)$ \\
\hline & Having fun & $1(1)$ & & Interpreting predictions & $8(6)$ \\
\hline & Hopeful & $4(2)$ & & Making predictions & $27(7)$ \\
\hline & & & & Next steps & $37(8)$ \\
\hline & & & & Testing predictions & $12(6)$ \\
\hline
\end{tabular}


[1] D. MacIsaac, Report: AAPT recommendations for the Undergraduate Physics Laboratory Curriculum, Phys. Teach. 53, 253 (2015).

[2] J. Fraser, A. L Timan, K. Miller, J. Dowd, L. Tucker, and E. Mazur, Teaching and physics education research: Bridging the gap, Rep. Prog. Phys. 77, 032401 (2014).

[3] F. Aparicio-Ting, D. Slater, and E. Kurz, Inquirybased learning (IBL) as a driver of curriculum: A staged approach, Papers on Postsecondary Learning and Teaching: Proceedings of the University of Calgary Conference on Learning and Teaching (2019), Vol. 3, pp. 44-51.

[4] D. R. Dounas-Frazer, J. T. Stanley, and H. J. Lewandowski, Student ownership of projects in an upper-division optics laboratory course: A multiple case study of successful experiences, Phys. Rev. Phys. Educ. Res. 13, 020136 (2017).

[5] S. Sjøberg, Constructivism and learning, in International Encyclopedia of Education, 3rd ed., edited by P. Peterson, E. Baker, and B. McGaw (Elsevier, Oxford, 2010), pp. 485-490.

[6] D. B. Luckie, J. J. Maleszewski, S. D. Loznak, and M. Krha, Infusion of collaborative inquiry throughout a biology curriculum increases student learning: A four-year study of "teams and streams", Adv. Physiology Educ. 28, 199 (2004).

[7] J. Arantika, S. Saputro, and S. Mulyani, Effectiveness of guided inquiry-based module to improve science process skills, J. Phys. Conf. Ser. 1157, 042019 (2019).

[8] S. J. Husnaini and S. Chen, Effects of guided inquiry virtual and physical laboratories on conceptual understanding, inquiry performance, scientific inquiry self-efficacy, and enjoyment, Phys. Rev. Phys. Educ. Res. 15, 010119 (2019).

[9] N. G. Holmes and D. A. Bonn, Quantitative comparisons to promote inquiry in the introductory physics lab, Phys. Teach. 53, 352 (2015).

[10] D. D. Minner, A. J. Levy, and J. Century, Inquiry-based science instruction-what is it and does it matter? Results from a research synthesis years 1984 to 2002, J. Res. Sci. Teach. 47, 474 (2010).
[11] E. M. Furtak, T. Seidel, H. Iverson, and D. C. Briggs, Experimental and quasi-experimental studies of inquirybased science teaching: a meta-analysis, Rev. Educ. Res. 82, 300 (2012).

[12] R. Spronken-Smith and R. Walker, Can inquiry-based learning strengthen the links between teaching and disciplinary research?, Studies Higher Educ. 35, 723 (2010).

[13] E. M. Furtak, R. J. Shavelson, J. T. Shemwell, and M. Figueroa, To teach or not to teach through inquiry, in The Journey from Child to Scientist: Integrating Cognitive Development and the Education Sciences, edited by S. M. Carver and J. Shrager (American Psychological Association, Washington, DC, 2012), pp. 227-244.

[14] L. B. Buck, S. L. Bretz, and M. H. Towns, Characterizing the level of inquiry in the undergraduate laboratory, J. Coll. Sci. Teach. 38, 52 (2008).

[15] Jupyter Notebook: An open-source programming language used in the laboratory course in this study, https://jupyter .org/.

[16] R. Martin, Q. Cai, T. Garrow, and C. Kapahi, QExPy: A Python-3 module to support undergraduate physics laboratories, SoftwareX 10, 100273 (2019).

[17] M. P. Silverman, Self-directed learning: A heretical experiment in teaching physics, Am. J. Phys. 63, 495 (1995).

[18] TRESTLE: Transforming education, stimulating teaching and learning excellence, http://trestlenetwork.org/.

[19] J. E. Kettler, The compact disk as a diffraction grating, Am. J. Phys. 59, 367 (1991).

[20] See Supplemental Material at http://link.aps.org/ supplemental/10.1103/PhysRevPhysEducRes.17.020109 for the CD diffraction lab manuals.

[21] Transcribe: Software used to transcribe audio recordings in this study, https://transcribe.wreally.com/.

[22] J. Corbin and A. Strauss, Basics of Qualitative Research: Techniques and Procedures for Developing Grounded Theory, 4th ed. (SAGE, Newbury Park, CA, 2015).

[23] D. R. Thomas, A general inductive approach for analyzing qualitative evaluation data, Am. J. Eval. 27, 237 (2006). 